\title{
Assessing the intelligence of a student through tic-tac-toe game for career guidance
}

\author{
J. Sasi Bhanu1, JKR Sastry ${ }^{2}$, V Chandra Prakash ${ }^{3}$ \\ ${ }^{1}$ CMR Institute of Technology, Kandlakoya Village, Medchal District, Hyderabad, India, ${ }^{2}$ Department of Electronics and \\ Computer Engineering, Koneru Lakshmaiah Education Foundation University, India \\ ${ }^{3}$ Department of Computer Science and Engineering, Koneru Lakshmaiah Education Foundation University, India
}

\section{Article Info}

Article history:

Received Sep 6, 2018

Revised Jun 29, 2019

Accepted Jul 17, 2019

\section{Keywords:}

Assessing psychological factors

Career guidance

Cognitive model

Expert system

Game playing

\begin{abstract}
It is necessary to assess various psychological factors of the student like Intelligence, patience, and perseverance for providing Career Guidance by an expert system apart from his/her academic record, Learning ability and Speed of solving the problem, etc. The outcome of this research work is an expert system called Tic-Tac-Toe Game Playing Career Guidance System (TTTGP-CGS) that is useful to assess the psychological factors of the student through Tic-Tac-Toe Game Playing, build the cognitive model of the student and predict the appropriate career(s) for the student. The system plays Tic-Tac-Toe game with the student several times. The average score obtained by the student reflects his/her intelligence. The average time taken by the student for playing the game reflects a student's speed of solving the problem. The number of attempts the student makes reflects the students' patience and perseverance. When the student plays the game with the system every day, if the student's score increases day by day, it reflects that the student has good learning ability. In this way, the system will assess the psychological factors of the student and builds the cognitive model of the student. Internally the system converts the quantitative scores into qualitative scores. The system maintains a table of careers and the expected levels of psychological factors that are required from a student's side to carry out the career successfully. The system invokes a matching process by considering the cognitive model of the student and the table of careers and predicts the career(s) suitable to the student.
\end{abstract}

Copyright $@ 2019$ Institute of Advanced Engineering and Science. All rights reserved.

\section{Corresponding Author:}

JKR Sastry,

Department of Electronics and Computer Engineering,

Koneru Lakshmaiah Education Foundation University,

Vaddeswaram, Guntur District, Andhrapradesh, India.

Email: drsastry@kluniversity.in

\section{INTRODUCTION}

An expert system for career guidance can identify suitable careers for a student basing on a cognitive model of the student. The cognitive model comprises of various psychological factors viz. Intelligence, Patience and perseverance, speed of solving the problem, Learning ability, etc. A Student can play a game with an expert system, and the system can assess the psychological factors of the students. By playing Tic-Tac-Toe game, assessing psychological factors becomes easy. A career guidance system can suggest suitable career(s) that suit a student. There are many ways to assess the Intelligence of a student that include Aptitude and Reasoning tests, IQ tests, etc. Other than these methods, Intelligence assessed while playing a game with a computer. 
Tic-Tac-Toe is an intelligent game that is useful to assess the psychological factors of the student viz. intelligence, Patience and perseverance, speed of solving the problem, Learning ability, etc. The Guidelines for playing Tic Tac Toe are as follows:

a. The game played between a human player (student) and a computer.

b. The choice is given to a human player (student) to decide whether the player can start the game or computer can start the game.

c. A $3 \times 3$ matrix is maintained internally to represent the current board position.

d. The mark ' $\mathrm{X}$ ' in a square represents the choice of the player. The mark ' $\mathrm{O}$ ' in a square represents the choice of the computer.

e. If any player arranges three marks in any one row or column or diagonal, then that player wins the game.

f. When all the nine squares are full, but nobody wins, then the game is concluded as Draw or tie.

Career guidance for a student is extremely important. Basing on the career(s) recommended by a human career expert, a student can select a better career path and select appropriate, essential, and elective courses during his/her UG/PG academic programs. Career guidance is also useful to the student during his/her final year of study to identify a suitable career(s) basing on his/her cognitive capabilities. Hence, it is essential for an Expert system for career guidance to assess the psychological factors like Intelligence of a student, build a cognitive model and predict the suitable career(s) for the student.

An expert system titled "Tic-Tac-Toe Game Playing and Career Guidance System (TTT-GP-CGS) "is to be designed and developed in Java, which plays Tic-Tac-Toe game with the student. It assesses the psychological factors of the student and suggests suitable career(s) for the student.

Objectives:

a. Assess the psychological factors of a student through Tic-Tac-Toe game playing.

b. Build the cognitive model of the student basing on the assessment.

c. Identify and suggest a suitable career(s) for the student basing on the cognitive model.

d. Establish correlation between the Intelligence factor assessed by the system and students' academic records.

\section{RELATED WORK}

It is very important to choose the proper career(s) for a student. Normally human experts select the appropriate career(s) for a student basing on his/her academic record. To err is human. That means while selecting the appropriate career, and even a human expert may commit error sometimes. Using AI Techniques, an expert system can be built to replace a human expert. That system can be used to decide which career(s) most suitable for a student. Apart from the academic track record of a student, various psychological factors like Intelligence, Speed of solving a problem, etc. of the student should be considered by the system to make a better decision regarding the selection of suitable career(s) for the student. Game Playing is one technique by which students psychological factors can be assessed. The following is the survey on the research work, namely Career guidance, Computer-based career guidance, Game-based career guidance. Career selection is one of the problems that is faced by the students to choose an appropriate career.

Waghmode, M. L. Jamsandekar [1] pointed out that the Expert system uses human knowledge stored inside a computer to solve problems that require human expertise for solving. The expert system helps with making a better decision. Computer-assisted career guidance to the students at the college level for selecting proper career stream is needed. These Computer-based career guidance systems help students to choose suitable jobs instead of making wrong decisions. George M. Papadourakis, Eva Foudoulaki, John E. Yannakoudakis, Marianna Alogdianaki [2] proposed a career counseling system which uses psychometrics to assess the personality of a person, the motives, the preferences for specific work environments, and the degree of sincerity in the answers given. Herr, Edwin L [3] pointed out that Career development mainly focuses on the psychological factors which will help to shape the future career and also helps in making effective career decisions over the life span. Roessler, Richard T., et al. [4] pointed out that Career planning is needed to identify the student's goals, problem-solving ability, their limitations and proper preparation for transition from education to work. Kelly M. Martincin and Graham B [5] Stead stated that there are multidimensional difficulties in making a career decision, and they are complex to solve. Driggs, Athanasios, et al. [6], in their paper, presented an expert system used for evaluating the performance of the students. The output produced by the system used for matching the student to a certain job position. For this purpose, it uses neuro-fuzzy logic. El Haji, Essaid, et al. [7] proposed that career guidance provided through a multiexpert system based on multi-agents. They said that different expert systems maintain a set of rules in the database, which helps in making the decision. Saraswathi, S., et al.[8] stated that Career guidance is also important when students need to select their undergraduate courses. The online expert system has 
a knowledge base that is used to give suggestions for the students to select their courses used for their future career.

Nowadays, game-based career guidance is becoming popular and more interesting for students. Therefore the games designed for career selection purpose must be designed with clear objectives and goals due to this the player will take the career decided by the system seriously for planning their career. In a game-based career assessment system, it should provide information about their capabilities, which helps them to find their interested and suitable career path. Dunwell et al. [9] have aimed for both qualitative and quantitative results of the game; this helps for better career paths and decisions. M. L. Waghmode, P. P. Jamsandekar., [10] Career decision is an important task in deciding which direction student must choose. While entering into Intermediate, a student has many options to choose, selection of proper career is very important. Yen-Ru Shi et al. [11] found that by designing a game, career planning carried, and it will become more successful than computer-assisted career guidance system. This game-based career planning will be more effective for the students. The advantage of game playing is to improve student's motivation and interest in finding the appropriate career(s) that suit the student. This paper mainly focuses on game-based career guidance, because while playing the game, it will provide entertainment for the students as well as it will be useful for career guidance. As the game was interesting students would play more games. Kevin Crowley and Robert S. Siegler [12] have conducted experiments and observed that students had followed three different strategies while playing Tic Tac Toe game and finally, they developed a computer-based Tic Tac Toe Simulation game. After this Survey, we got the idea that we can develop an expert system that plays Tic-Tac-Toe game with a student and assesses the psychological factors of the student like Intelligence, etc. Based on the scores computed for a student, the system can predict the most suitable career(s) for the student.

\section{DESIGN OF TTT-GP-CGS}

Career assessment is the most important to decide individual career for knowing their suitable job. In this Paper the assessment is done based on Tic Tac Toe game through this game some of the knowledge factors such as Intelligence, Learning ability, Regularity, Speed of play, Patience and Perseverance of the student assessed. Figure 1 shows the system architecture of Tic-Tac-Toe.

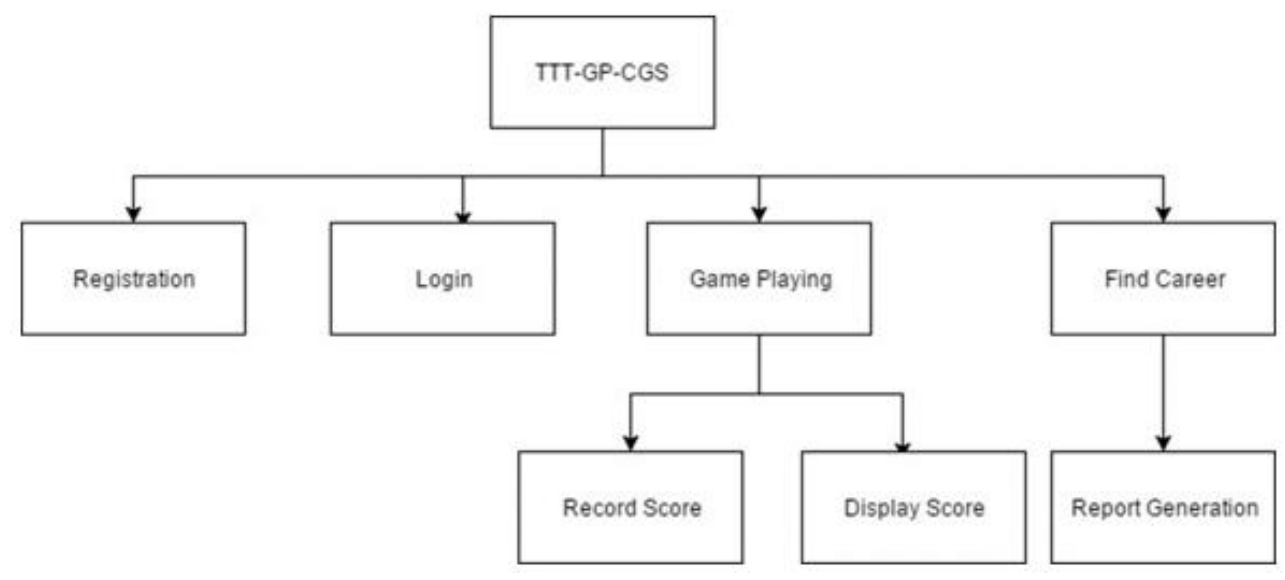

Figure 1. The system architecture of TTT-GPCGS

\subsection{Registration}

Using this module, a new student can register his name and other particulars. The student has to enter information regarding his/her name, college registration number, Mobile number, Program of Study, Year of Studying, CGPA (or) Percentage, etc. The student has to enter his password and confirm it. The system will create a separate file for every student and stores the details of the student.

\subsection{Login}

During the Login process, the student enters his register number and password. The password is verified, and the system allows the student to play the game. This module is for security purpose. 


\subsection{Game playing}

After the login, the process completed, the Tic-Tac-Toe game can be started by the player. The game played for any number of times per day. (The minimum number recommended is ten). In this game playing module total score accrued will be calculated, and also a time of play will be calculated, i.e., when the player started and ended the game. After completion of the game playing session, the score recorded - the score of the student displayed with the score display module.

\subsection{Assessing psychological factors}

TTT-GP-CGS plays Tic-Tac-Toe game several times with a student, and the scores recorded. These scores are processed to assess the psychological factors of the student in the building the cognitive model of the student. The following procedure is adopted.

\subsubsection{Assessing intelligence}

From the scores obtained during game playing, the average score of the student computed. This score reflects the intelligence of the student. The average score obtained quantitatively. The score is converted in qualitative terms using Table 1.

Table 1. Intelligence-quantitave to qualitative conversion table

\begin{tabular}{ccc}
\hline S. No. & Average Score(Quantitative) & Qualitative \\
\hline 1. & $>=0.45$ and above & Very high \\
2. & $>=0.3 \&<0.45$ & High \\
3. & $>=0.2 \&<0.3$ & Moderate \\
4. & $<0.2$ & Low \\
\hline
\end{tabular}

\subsubsection{Assessing the speed of solving the problem}

The time consumed by a student after playing each game recorded. The average time of play computed in quantitative terms. The time computation reflects the student's speed of solving the problem. The score converted into qualitative terms using Table 2.

Table 2. Speed of solving problem -quantitative to qualitative conversion table

\begin{tabular}{ccc}
\hline S. No. & Speed of solving problem (Quantitative) & Qualitative \\
\hline 1. & $<=40 \mathrm{sec} /$ game & Fast \\
2. & $>40 \mathrm{Sec} \&<=1 \mathrm{~min}$ & Moderate \\
3. & $>1 \mathrm{~min} \&<=2 \mathrm{~min}$ & Slow \\
4. & $>2 \mathrm{~min}$ & Very Slow \\
\hline
\end{tabular}

\subsubsection{Assessing the patience $\&$ perseverance}

The number of games played (NGP) by the student first recorded. The number of games played by a student reflects the student's patience and perseverance. The minimum number of games recommended is 30 . The NGP can be converted into qualitative terms using Table 3 .

Table 3. Patience \& perseverance - quantitative to qualitative conversion table

\begin{tabular}{ccc}
\hline S. No. & Number of games played (Quantitative) & Qualitative \\
\hline 1. & $>=30$ & Very high \\
2. & $>=20 \&<30$ & High \\
3. & $>=10 \&<20$ & Moderate \\
4. & $<10$ & Low \\
\hline
\end{tabular}

\subsubsection{Learning ability}

The student plays a minimum of 50 games for assessing the learning ability of a student. The learning ability of a student not assessed, If the number of games played is less than 50 . The following equation is used to compute the learning ability index (LAI), as shown in Table 4 . For assessing Learning ability, 
Table 4. Learning ability index - quantitative to qualitative conversion table

\begin{tabular}{ccc}
\hline S. No. & Quantitative & Qualitative \\
\hline 1. & LAI $>=6$ & High \\
2. & LAI $>=3 \&$ LAI $<=5$ & Moderate \\
3. & LAI $<3$ & Low \\
\hline
\end{tabular}

\subsection{Finding suitable careers}

Generally, a student is selected for a career depending on his/her academic track record that is reflected by Cumulative Grade Point Average (CGPA). We propose that, apart from the candidate's CGPA, the various psychological factors considered while selecting a suitable career for the student. Table 5 shows some identified careers, CGPA, and quality of various psychological factors required to perform the job.

\subsubsection{Assessing learning ability (LA)}

Consider the number of games played by the student. For every ten games played, compute average score (AS). Now consider all those average scores. If they are in increasing order, then it reflects that the student has Earlier, various psychological factors of the student assessed both quantitatively and qualitatively. A matching process carried on to match the student's psychological factors with those factors of each career, as shown in Table 5, and the suitable careers recommended. A Report displays the career(s) suitable to the students.

Table 5. Career VS required academic record and psychological factors

\begin{tabular}{|c|c|c|c|c|c|c|}
\hline \multirow[t]{2}{*}{ S. No. } & \multirow[t]{2}{*}{ Career } & \multirow[t]{2}{*}{ CGP A } & \multicolumn{4}{|c|}{ Quality of Psychological Factor } \\
\hline & & & Intelligence & $\begin{array}{c}\text { Speed of } \\
\text { Solving problems }\end{array}$ & $\begin{array}{l}\text { Patience and } \\
\text { perseverance }\end{array}$ & $\begin{array}{l}\text { Learning Ability } \\
\text { (optional) }\end{array}$ \\
\hline 1 & Software Engineer & $>=7.5$ & Very High & Fast & Moderate & High \\
\hline 3 & Software Tester & $>=6.5$ & Moderate & Slow & Moderate & Moderate \\
\hline 4 & Marketing Person & $>=6.5$ & Low & Slow & High & Low \\
\hline$\ldots$ & $\ldots$ & $\ldots$ & $\ldots$ & $\ldots$ & $\ldots$ & $\ldots$ \\
\hline
\end{tabular}

\section{RESULT ANALYSIS}

A set of final year B. Tech (Computer science and engineering) students played with TTT-GPCGS and the scores of the students recorded by the system. The system found a suitable career(s) to the students are basing on the assessed psychological factors that match to the career(s). Table 6 gives an example of results. The student's registered number, CGPA, psychological factors, and the highest career for which he/she is suitable shown in Table 6.

Table 6. Student VS recommended career(s)

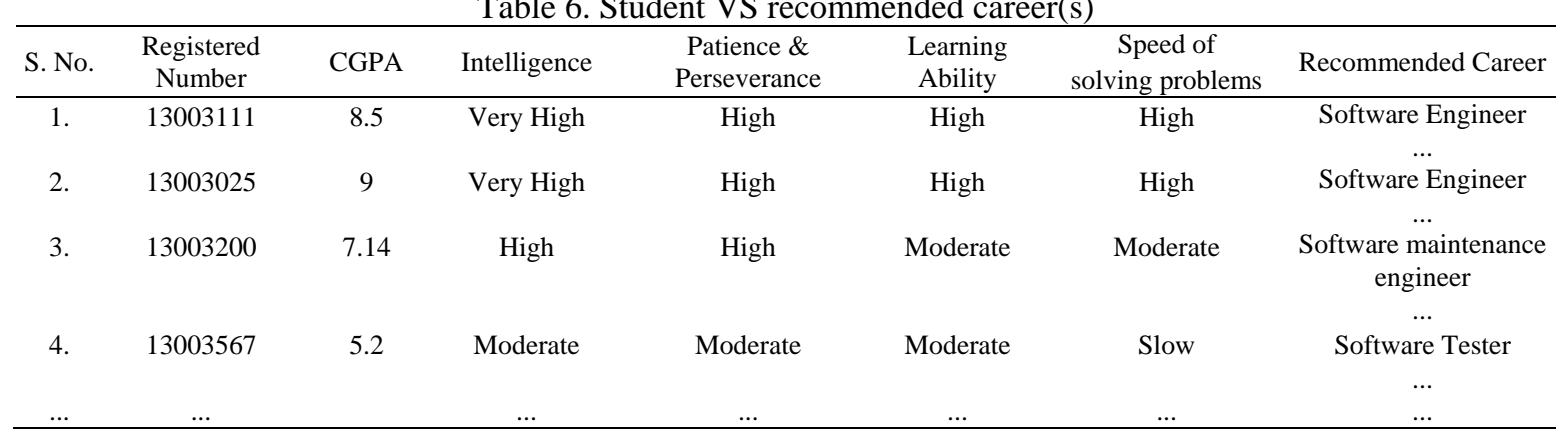

We can observe, in general, that if a student exhibits good intelligence, he/she also gets good marks and maintains a good academic record. We tried to prove this hypothesis. Of course, it is possible that a student with high intelligence may not study well and may not obtain good CGPA. It is also possible that a student with average intelligence may obtain a higher CGPA than expected. There are some reasons for this anomaly. For example, that student may have a very high memory power. Table 7 shows student's Intelligence score and CGPA. A graph, as shown in Figure 2, plotted by taking Intelligence score on the $\mathrm{x}$-axis and the student's CGPA on the y-axis. 
Table 7. Intelligence score and CGPA

\begin{tabular}{cccc}
\hline S. No. & Register no. & Intelligence & CGPA \\
\hline 1. & 13003463 & 0.13 & 4.20 \\
2. & 13003567 & 0.25 & 5.20 \\
3. & 13003150 & 0.40 & 5.50 \\
4. & 13003566 & 0.25 & 6.00 \\
5. & 13003368 & 0.35 & 6.90 \\
6. & 13003200 & 0.35 & 7.14 \\
7. & 13003301 & 0.40 & 7.30 \\
8. & 13003104 & 0.35 & 7.70 \\
9. & 13003082 & 0.40 & 8,00 \\
10. & 13003161 & 0.45 & 8.40 \\
11. & 13003111 & 0.45 & 8.50 \\
12. & 13007237 & 0.50 & 8.50 \\
13. & 13003025 & 0.50 & 9,00 \\
\hline
\end{tabular}

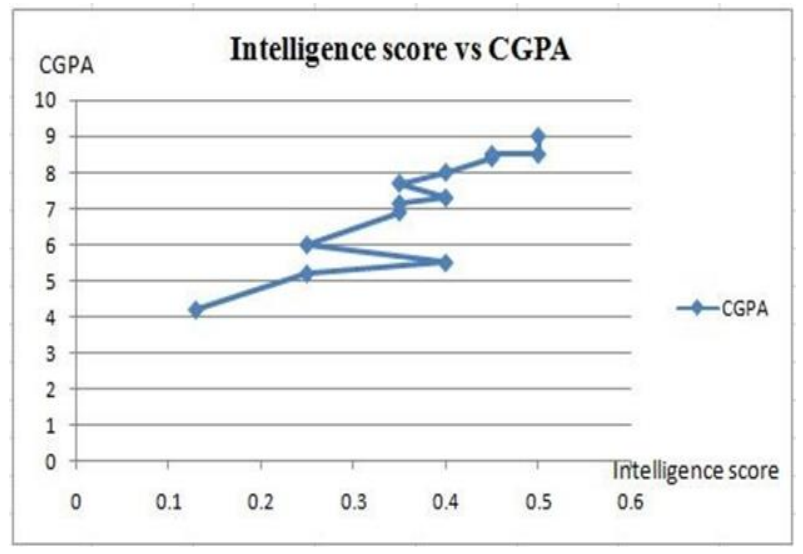

Figure 2. Intelligence score vs. CGPA

In Figure 2, one can observe that a student, who has high intelligence, has low CGPA. The reason behind this may be that either the student is not having good memory power or lack of interest in that particular course. By removing such odd students, the graph became linear to some extent as shown in Figure 3. A correlation is established between CGPA and Intelligence score, as shown in Table 8. That is, the students who are having good intelligence have good CGPA, and predicted the most suitable career(s) for the students. A correlation between intelligence score and the students' academic track record established, and this shows that the system is rightly assessing the psychological factors of the student. We have considered important job positions in a software career so that the system can predict the appropriate career(s) for the students of B.E./B. Tech of computer science and engineering and other engineering branches. The number of careers (s) extended so that the system will be useful for any graduate or postgraduate students.

Table 8. Intelligence score and CGPA -revised

\begin{tabular}{cccc}
\hline S. No. & Register no. & Intelligence & CGPA \\
\hline 1. & 13003463 & 0.13 & 4.20 \\
2. & 13003567 & 0.25 & 5.20 \\
3. & 13003566 & 0.25 & 6.00 \\
4. & 13003368 & 0.35 & 6.90 \\
5. & 13003200 & 0.35 & 7.14 \\
6. & 13003301 & 0.40 & 7.30 \\
7. & 13003082 & 0.40 & 8.00 \\
8. & 13003161 & 0.45 & 8.40 \\
9. & 13003111 & 0.45 & 8.50 \\
10. & 13007237 & 0.50 & 8.50 \\
11. & 13003025 & 0.50 & 9.00 \\
\hline
\end{tabular}




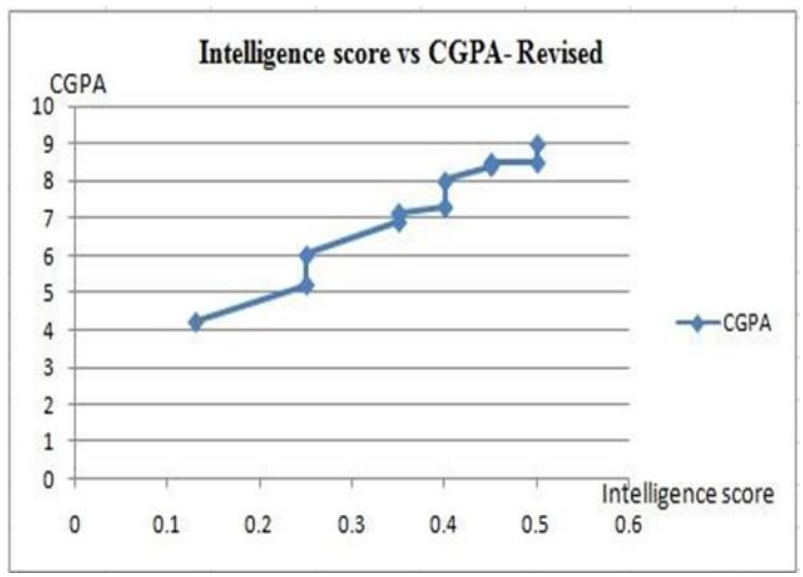

Figure 3. Revised intelligence vs. CGPA

\section{CONCLUSIONS}

Any Career guidance system is extremely important for a student as it can recommend the best career(s) suitable for the student so that he/she can be advised/guided to go through the appropriate path. Apart from the academic record of a student, the psychological factors of the student also play a major role while deciding the best career(s) for a student. Though there are many traditional tests like Aptitude and reasoning tests, IQ tests, etc. that are used to assess the psychological factors of a student, the novel idea is to assess the psychological factors through game playing because playing the game is much more interesting for every student instead of attending other general tests. TTT-GP-CGS has successfully implemented this idea. It played Tic-Tac-Toe game with some students of our university, built the cognitive models of the students.

\section{FUNDING}

This research work is part of the research project titled "Development of an expert system for career assessment based on the cognitive model" funded by Department of Science and Technology - Cognitive Science Research Initiative scheme(CSRI) (Sanction order No SR/CSRI/129/2014(G)) of Government of India. The infrastructure for the project provided by K L University.

\section{REFERENCES}

[1] M. L. J. Waghmode, “A study of an expert system for career selection: Literature review," International Journal of Advanced Research in Computer Science and Software Engineering, vol. 5, pp. 779-85, 2015.

[2] G. M. Papadourakis, et al., "An Expert Systems Approach to Career Counselling," New Horizons In Industry, Business And Education, pp. 71.

[3] E. L. Herr, "Career development and its practice: A historical perspective," The Career Development Quarterly, vol. 49, pp. 196-211, 2001.

[4] R. T. Roessler, et al., "Career Assessment and Planning Strategies for Postsecondary Students with Disabilities," Journal of Postsecondary Education and Disability, vol. 21, pp. 126-137, 2009.

[5] K. M. Martincin and G. B. Stead, "Five-Factor Model and difficulties in career decision making: A meta-analysis," Journal of Career Assessment, vol. 23, pp. 3-19, 2015.

[6] A. Drogas, et al., "An expert system for job matching of the unemployed," Expert Systems with Applications, vol. 26, pp. 217-224, 2004.

[7] E. El Haji, et al., "Multi-expert system design for educational and career guidance: an approach based on a multi-agent system and ontology," International Journal of Computer Science Issues (IJCSI), vol. 11, pp. 46, 2014.

[8] S. Saraswathi, et al., "Design of an online expert system for career guidance," IJRET: International Journal of Research in Engineering and Technology, 2014.

[9] Dunwell, et al., "MeTycoon: A game-based approach to career guidance," Games and Virtual Worlds for Serious Applications (VS-GAMES), IEEE 2013 5th International Conference on, Poole, pp. 1-6, 2013.

[10] M. L. Waghmode and P. P. Jamsandekar, "Expert system for Career Selection: A Classifier Model," International Journal of Advanced Research in Computer Science and Management Studies, vol. 4, 2016.

[11] Y. R. Shi and J. L. Shih, "Game-Based Career Guidance Systems Design Concept," Digital Game and Intelligent Toy Enhanced Learning (DIGITEL), 2012 IEEE Fourth International Conference on. IEEE, 2012.

[12] K. Crowley and R. S. Siegler, "Flexible Strategy Use in Young Children's Tic-Tac-Toe," CognitiveScience, vol. 17 , pp. 531-561, 1993.

Assessing the intelligence of a student through tic-tac-toe game for career guidance (J. Sasi Bhanu) 